\title{
Age specific xerophthalmia rates among displaced Ethiopians
}

\author{
L D PIZZARELLO
}

Helen Keller International Inc, New York, United States of America

SUMmaRY The recent famine in Ethiopia has resulted in the dislocation of millions of people. Many of these individuals have moved to refugee camps in Sudan or to feeding centres within Ethiopia.

A total of 1325 children up to the age of 15 years were examined by an ophthalmologist in January 1985 at several sites in these two countries. The rates of Bitot's spots were three times greater in those between the ages of 7 and 10 compared with those under 7 . Rates of corneal xerosis were comparable for each group. Previously, xerophthalmia was considered predominantly to affect children aged under 6 . These data document the presence of the disease in older children and raise questions regarding future modifications in the prevention and treatment of xerophthalmia.

Xerophthalmia has been recognised as one of the leading causes of childhood blindness in most developing countries. ${ }^{1}$ Initially found in high rates in Asia, recent reports clearly show considerable problems with vitamin A deficiency on the African continent. $^{2}{ }^{3}$ The presence of large numbers of children in areas of drought and political upheaval has resulted in mass starvation and attendant to that some of the highest rates of xerophthalmia ever recorded. ${ }^{4}$

Traditionally, xerophthalmia has been considered to have peak prevalence in children 2-6 years of age. ${ }^{5}$ Because of the severity of the nutritional situation in Ethiopia, all children up to 14 were considered at high risk for malnutrition and so were included in this assessment.

\section{Patients and methods}

In January 1985 a rapid assessment was carried out to determine the extent of xerophthalmia among children from birth to 14 years of age who were affected by the recent drought in Ethiopia. Children were seen at several sites, located at two refugee centres in the Sudan that housed Ethiopians as well as at feeding centres within Ethiopia itself. Transport limitations necessitated that only these areas were visited. At each site children were sampled from as many different settings as possible to broaden the representation of the population at risk.
All children had been subjected to severe deprivation and starvation in the preceding months.

An ophthalmologist (LDP) saw each child, asking for age and sex, and then, using a handlight, examined the ocular adnexa, conjunctiva, cornea, and anterior chamber. Visual acuity was estimated to be better or worse than $3 / 60$ based on clinical signs. Whenever possible, children with appreciable corneal scarring or blindness were examined as thoroughly as possible, given the field conditions. Any informant present with the child was queried concerning clinical history, and every attempt was made to assign an aetiology to each case of important ocular disease. Children with any signs of active xerophthalmia were treated appropriately.

\section{Results}

Children were examined at several sites in both countries, as summarised in Table 1 . The subsites where the assessment was performed are listed as

Table 1 Children examined categorised by site

\begin{tabular}{llll}
\hline Site & Type & Population & $\begin{array}{l}\text { No of } \\
\text { children } \\
\text { examined }\end{array}$ \\
\hline Wad, Kowli, Sudan & Refugee camp & 50000 & 518 \\
Wad Sheriffe, Sudan & Refugee camp & 80000 & 166 \\
Alamata, Ethiopia & Feeding centres & Not applicable & 641 \\
\hline
\end{tabular}


well as the population of the sites at the time of the assessment and the nature of the setting.

A total of 1325 children was examined for whom age and sex were available, and the information is given in Table 2. Sixty four cases of xerophthalmia in any of its manifestations, except night blindness, were found, giving an overall rate of $4 \cdot 8 \%$. The age specific rates for the various manifestations of xerophthalmia for each site are given in Tables 3-5.

Table 2 Children examined categorised by age and sex

\begin{tabular}{lccc}
\hline Age (years) & Boys & Girls & Total \\
\hline $0-1$ & 55 & 49 & 104 \\
2 & 80 & 88 & 168 \\
3 & 64 & 57 & 121 \\
4 & 64 & 66 & 130 \\
5 & 66 & 64 & 130 \\
6 & 59 & 38 & 97 \\
7 & 66 & 51 & 117 \\
8 & 60 & 49 & 109 \\
9 & 42 & 33 & 75 \\
10 & 96 & 74 & 170 \\
11 & 11 & 12 & 23 \\
12 & 31 & 11 & 42 \\
13 & 13 & 6 & 19 \\
14 & 12 & 8 & 20 \\
\hline Total & 719 & 606 & 1325 \\
\hline
\end{tabular}

Table 3 No of cases (rate/1000) of Bitot's spots categorised by age and sex

\begin{tabular}{lllr}
\hline Age (years) & \multicolumn{1}{c}{ Boys } & Girls & Total \\
\hline $0-6$ & $5(12 \cdot 9)$ & $2(5 \cdot 5)$ & $7(9 \cdot 3)$ \\
$7-14$ & $14(42 \cdot 9)$ & $5(20 \cdot 7)$ & $19(33 \cdot 5)$ \\
\hline All & $19(26 \cdot 6)$ & $7(11 \cdot 6)$ & $26(19 \cdot 7)$ \\
\hline
\end{tabular}

Table 4 No of cases (rate/1000) of corneal xerosis categorised by sex and age

\begin{tabular}{lllr}
\hline Age (years) & Boys & Girls & \multicolumn{1}{l}{ Total } \\
\hline $0-6$ & $3(7 \cdot 7)$ & $8(22 \cdot 1)$ & $11(14 \cdot 7)$ \\
$7-14$ & $4(12 \cdot 3)$ & $2(8 \cdot 3)$ & $6(10 \cdot 6)$ \\
\hline All & $7(9 \cdot 8)$ & $10(16 \cdot 5)$ & $17(12 \cdot 9)$ \\
\hline
\end{tabular}

Table 5 Other cases of xerophthalmia than those listed in Table 4 categorised by age and sex

\begin{tabular}{lllll}
\hline $\begin{array}{l}\text { Age } \\
\text { (years) }\end{array}$ & $\begin{array}{l}\text { Corneal } \\
\text { scars }\end{array}$ & $\begin{array}{l}\text { Phthisis } \\
\text { bulbi }\end{array}$ & $\begin{array}{l}\text { Kerato- } \\
\text { malacia }\end{array}$ & $\begin{array}{l}\text { Blind* } \\
\text { second degree } \\
\text { xerophthalmia }\end{array}$ \\
\hline $0-6$ & 3 & 1 & 5 & 3 \\
$7-14$ & 8 & 2 & 2 & 3 \\
\hline All & 11 & 3 & 7 & 6 \\
\hline
\end{tabular}

*Includes those already appearing in this Table.

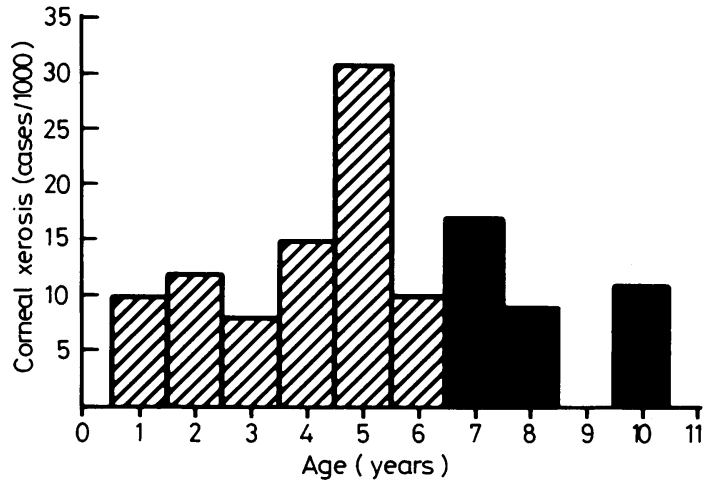

Fig. 1 Age specific rates of Bitot's spots per thousand for the population studied.

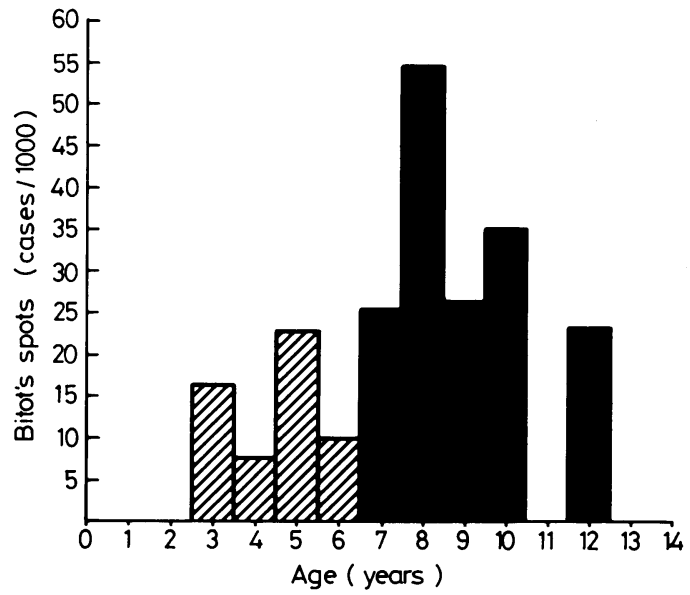

Fig. 2 Age specific rates of corneal xerosis per thousand for the population studied.

The ages were combined into two groups, 0.6 years and 7-14 years, for ease of comparison and to improve accuracy in age reporting as well as analysis.

The $\chi^{2}$ test was used to evaluate the significance between age groups for each condition (for either condition there was no significant difference between sex). Figures 1 and 2 show the age specific rates for Bitot's spots and corneal xerophthalmia for the entire population examined.

\section{Discussion}

The recent famine has had a devastating effect on the people of northern Ethiopia. The resultant malnutrition has been as bad or worse as any seen 
previously. One would expect all nutritional deficiency diseases, particularly vitamin A deficiency, to be found in high rates in this population. Clearly, this has been the case as has been reported and can be seen in these results. Overall, $4.8 \%$ of the population studied (children from birth to 14 years of age) had some clinical signs of xerophthalmia. This is greater than rates seen in previous refugee populations ${ }^{6}$ and is as high or higher than those rates seen in previous prevalence surveys in Asia. ${ }^{2} 78$

Xerophthalmia prevalence surveys performed recently have tended to be limited to children aged under 7. The World Health Organisation guidelines for control of xerophthalmia state that children aged under 6 are most at risk for developing the disease and therefore suggest concentrating on this age group during assessments. Various authors have reported peak rates of corneal xeroses and Bitot's spots in 3 to 4 year olds, with a drop off in rates after the age of 5 . Solan et al, however, reported persistence of the signs of active xerophthalmia in all age groups up to 16 in the Philippines. ${ }^{2}$ Similar data have been gathered in Bangladesh. ${ }^{3}$

Sommer, in an exhaustive study in Indonesia, has found that while Bitot's spots may be seen in children over 6 , the percentage of these lesions that do not respond to administration of vitamin A rises rapidly. ${ }^{7}$ These so called 'vitamin A resistant' Bitot's spots may not represent a manifestation of the deficiency.

Because of the extreme degree of global malnutrition in the Ethiopian situation, I elected to examine all children up to 14 years of age. The circumstances in which this assessment was performed were not conducive to rigorous sample selection. Refugee camps and feeding centres have population shifts on a daily basis. The need to feed thousands of individuals took precedence over any systematic registration or monitoring activities. Whenever possible, multiple examination sites were chosen in the various locations. All children were seen who were either living at or who had gathered at the examination site. No children were included who were receiving hospital care. Every effort was made to examine a representative sample of the population. The limitations of the sampling technique made stratification impossible; the data do show consistent trends, however, in prevalence of xerophthalmia.

No demographic data existed for the population sampled. It would be expected that a typical population pyramid in developing countries would have $35-50 \%$ of the population below 15 . High child mortality in this population may have altered that rule. More children aged under 6 were examined (750) than those aged 7 and over (567). Boys comprised $54 \%$ of those examined, which may represent a bias toward male preservation in such a dramatic situation. Age was provided by the parent or guardian when available or by the examinee in older age groups. There were no documents available to verify age, and clearly some rounding off of age does occur, as seen by a large cluster of children aged 10, with fewer at 9 and 11 years. Any gross discrepancies between stated age and appearance of the child led to more extensive questioning and attempts to assign age more accurately.

Age specific rates for Bitot's spots show a pronounced shift toward older age groups (Fig. 1). The peak prevalence occurs at 8 years, with a greater than threefold increase in prevalence for those 7 and older compared with the younger group, a difference that was significant to the $\mathrm{p}<0.01$ level. Conceivably, some of these cases may not be related to xerophthalmia, yet even allowing for these, many Bitot's spots related to xerophthalmia would be found in this group. The rates for corneal xerosis show considerably less of the shift to older ages (Fig. 2 ). The ratio of corneal xerosis prevalence for those aged $\leqslant 6$ compared with those $>6$ is $1 \cdot 4: 1$. One third of the cases of corneal xerosis seen would have been missed if those aged 7 and over had not been examined. Statistical evaluation by $\chi^{2}$ test of these data showed no significant difference in the rates between the two age groups for either sex. Relatively few children between the ages of 11 and 14 were seen. The cases of xerophthalmia in this group, therefore, can yield dramatically high prevalences for these age groups. It can be said that cases of xerophthalmia were seen in this group over 10 , but the true significance of this problem remains for further elucidation.

The other clinical manifestations of xerophthalmia were seen less often (Table 3-5). Eleven corneal scars compatible with xerophthalmia were seen, eight of them in children aged over 7. Phthisis bulbi was evident in three cases, two of whom were aged over 7. Active keratomalacia, rarely seen in a prevalence survey, was present in seven children, five of whom were aged 6 or less. Six children were blind from presumed xerophthalmia, three in each age group.

The tragedy of Ethiopia has an added dimension of childhood blindness caused by xerophthalmia. This blindness remains preventable if massive doses of vitamin A supplementation can take place. Such a distribution was begun in Ethiopia and Sudan in 1985 , in large part based on this assessment. Inclusion of children up to the age of 14 resulted in recognition of many active cases of xerophthalmia and some potentially blinding ones. It seems appropriate to alter the guidelines for treating 
xerophthalmia, particularly in drastic situations like the case in Ethiopia, to include children at least to age 10 in both assessment and prevention activities.

\section{References}

1 Sommer A. Field guide to the detection and control of xerophthalmia, Geneva: WHO, 1978:5.

2 Solon FS, Popkin BM, Fernandez TL, Latham MC. Vitamin A deficiency in the Philippines: a study of xerophthalmia in Cebu. Am J Clin Nutr 1978;31:360-8.

3 Cohen N. Bangladesh nutritional blindness study. New York: Helen Keller International, 1985.

${ }^{4}$ Pizzarello LD. Xerophthalmia rates in Ethiopia and the Sudan. Am J Ophthalmol 1985;99:734.
5 Oomen HAPC. Clinical epidemiology of xerophthalmia in man. Am J Clin Nutr 1969;22:1098-1105.

6 Pizzarello LD. Xerophthalmia rates in Kampuchean refugees in Thailand. New York: Helen Keller International, 1980.

7 Sommer A. Nutritional blindness. New York: Oxford University Press, 1982.

8 Brink EW, et al. Vitamin A status of children in Sri Lanka. Am J Clin Nutr 1979;32:84-91.

Correspondence to Dr L D Pizzarello, Helen Keller International Inc, 137 Hampton Road, Southampton, New York 11968, United States of America.

Received 4 June 1986

British Paediatric Association

Annual meetings

At York University:

1987 April 7-10

1988 April 12-16

1989 April 11-15

At University of Warwick:

1990 April 3-7

1991 April 16-20

1992 April 7-11

1993 April 19-23 (provisional)

1994 April 11-15 (provisional) 